\title{
Telegram Bot Integration with Face Recognition as Smart Home Features
}

\author{
Ngurah Made Ardika \\ Department of Information \\ Technology, Faculty of \\ Engineering Udayana \\ University, Bukit Jimbaran, \\ 80361, Indonesia
}

\author{
Nyoman Piarsa \\ Department of Information \\ Technology, Faculty of \\ Engineering Udayana \\ University, Bukit Jimbaran, \\ 80361 , Indonesia
}

\author{
Arya Sasmita \\ Department of Information \\ Technology, Faculty of \\ Engineering Udayana \\ University, Bukit Jimbaran, \\ 80361, Indonesia
}

\begin{abstract}
The development of science is very rapid which makes us easier to do practical activity based on the emergence of technology which is able to control electronic devices in the house from a distance which is called Smart Home. Facial detec-tion systems are also growing. The technology of controlling electronic devices using remote control is helpful in managing the electronic devices in order to control and monitor every human faces who entered the house. A system created to detect and recognize human faces is using a mini PC Raspberry Pi 3 with a camera module (webcam). Human face detection and recognition utilize a library in OpenCV, where it is used to detect, create databases and match new faces with databases. Face recognition will be a system user notification using the Telegram Bot app. Telegram Bot as remote control and receive notification from system. Out of 25 identification trials, the success rate or SR of face identification test was $84 \%$ and the False Accet Rate or FAR was $16 \%$. Some important factors that influence the success rate of identifications are the position of the face and the intensity of the light during the process of making data train.
\end{abstract}

\section{General Terms}

OpenCV Library, computer vision, Telegram Bot Integration.

\section{Keywords}

Smart Home, Face Recognition, Telegram Bot.

\section{INTRODUCTION}

The development of science makes us able to do practi-cal activities, marked by the emergence of technology that is able to control objects remotely using the internet. The concept of this technology is better known as the Internet of Things (IoT). IoT connects new equipment and envi-ronments, such as kitchens, engine rooms, health and transport facilities, to the internet. With IoT, humans can easily control various devices and systems as a whole, effi-ciently and securely. Smart House Systems using face de-tection and recognition methods will provide security and comfort for homeowners and people living in it, as it can detect the faces of everyone entering the house. Facial recognition is one of the most widely applied biometric technologies in security system.

The related research of the identification system imple-mented by Darma Putra under the title "High Performance Palmprint Identification System Based on Two Dimension-al Garbor" which aims to introduce the palmation ROI segmentation method of two-stage center point and apply two-dimensional Garbor method to generate palm code as a feature palms and using the hamming distance method to measure the similarity level of two palm vectors [2]
The related research of identification system imple-mented by Dwi Rusjayanthi under the title "Identifikasi Biometrika Telapak Tangan Menggunakan Metode Pola Busur Terlokalisasi, Block Standar Deviasi, dan K-Means Clustering" do the testing of the palm identi-fication system with 94\% accuracy level using a normal-ized method with scaling and multiplier coefficients. The clustering process with k-means algorithm resulted in a low-er accuracy rate of $92 \%$. Time savings of $45.04 \%$ with $\mathrm{k}$-means for clustering in the standard deviation block method [3]

Another research is "Rancang Bangun Prototipe Sistem Monitoring dan Kontrol Visual Keamanan Rumah Ber-biaya murah" by Piarsa I Nyoman, Suar Wibawa, Arya Sasmita and Adi Purnwan in 2016 utilizing Raspberry pi mini computer device, two usb camera module, using In-stant Messenger that is Telegram messenger which has sev-eral features created with the Python programming lan-guage including System menu features in the Messenger Telegram app, a service request picture from all cameras, an picture query service separately from camera 1 and camera 2 as well as video service requests from camera 1 and camera 2 . The advantages of this systems are in terms of cost, flexibility of device placement, flexibility in terms of access and flexibility in future development. [4]

Another research is "Face Recognition Using Eigenface Approach*" by Marijeta Slavković1 and Dubravka Jevtić1 in 2012 Face recognition method using eigenfaces is proposed. used database of face images which contains 190 images of 38 different persons. From the results, it can be concluded that, for recognition, it is sufficient to take about $10 \%$ eigenfaces with the highest eigenvalues. It is also clear that the recognition rate increases with the number of training images per person. It is obvious that if the minimum distance between the test image and other images is zero, the test image entirely matches the image from the training base. If the distance is greater than zero but less than a certain threshold, it is a known person with other facial expression, otherwise it is an unknown person.[9]

Based on the above explanation, the research entitled "Telegram Bot Integration with Face Recognition as Smart Home Features" was appointed to develop and test the facial identification technology in smart home by using OpenCV library and remote control using Telegram Instant Messenger app.

\section{REALETED WORK}

A face contains lots of readable feature information, such as: eyes, nose and mouth. Facial recognition system is a system that performs engineering methods in an image to find the identity or information contained in the image. Facial 
recognition system is generally divided into two, namely face detection and facial recognition [1]. In general, the location of the eye is the point used to recognize the face [5]. There are two ways to collect facial data. First with an image acquisition by registering faces directly in to the application and the second by using the existing face da-tabase, for example Casia-FaceV5 [6]. Techniques that can be used to detect faces in an image, such as: Geome-try-based Methods, Color-based Approaches, Appear-ance-based Methods, Template Matching Methods. Fac-tors that are often become a problem in the detecting the faces are factor of poses, structural components, rotation of images, facial expression, unnatural intensity, facial conditions, and light intensity.

The integration of bot telegram with face recognition as a smart home feature will apply face detection and recognition by using OpenCV libraries processed using Raspberry Pi 3 as a means of real-time face detection and recognition. The supervision can be done remotely by using Instant Messenger such as Telegram Bot, Telegram and Raspberry Pi 3 which can communicate both ways.

\section{RESEARCH METHOD}

The research method used is SDLC (Software Development Life Cycle) waterfall model. The Waterfall model is the most popular model among other approach models in the SDLC.
Waterfall model is a development model that works in linear and sequence and also this model is the first model which is formed. Each stage must be completed before continue to the next stage. The research flow is required as a reference or research framework, so that it can obtain a conceptual outcome. The groove used in designing Telegram Bot integration sys-tem with face recognition:

1. Defining the built application.

2. Identify problems that occur, related to the built system.

3. Determine the aims of the research of recognition system Smart House / Home Features.

4. Collecting the data and literature reviews related to the making of the system.

5. Modeling the system by collecting and understanding the things that can happen in the application.

6. Designing and developing systems such as database design as the location of data storage and the making of application program code.

7. Testing the system and documentation of the results.

8. Taking conclusions from the tests conducted.

\section{SYSTEM OVERVIEW}

An overview of Telegram Bot's integration system with face recognition as a smart home feature is shown in Figure 1.

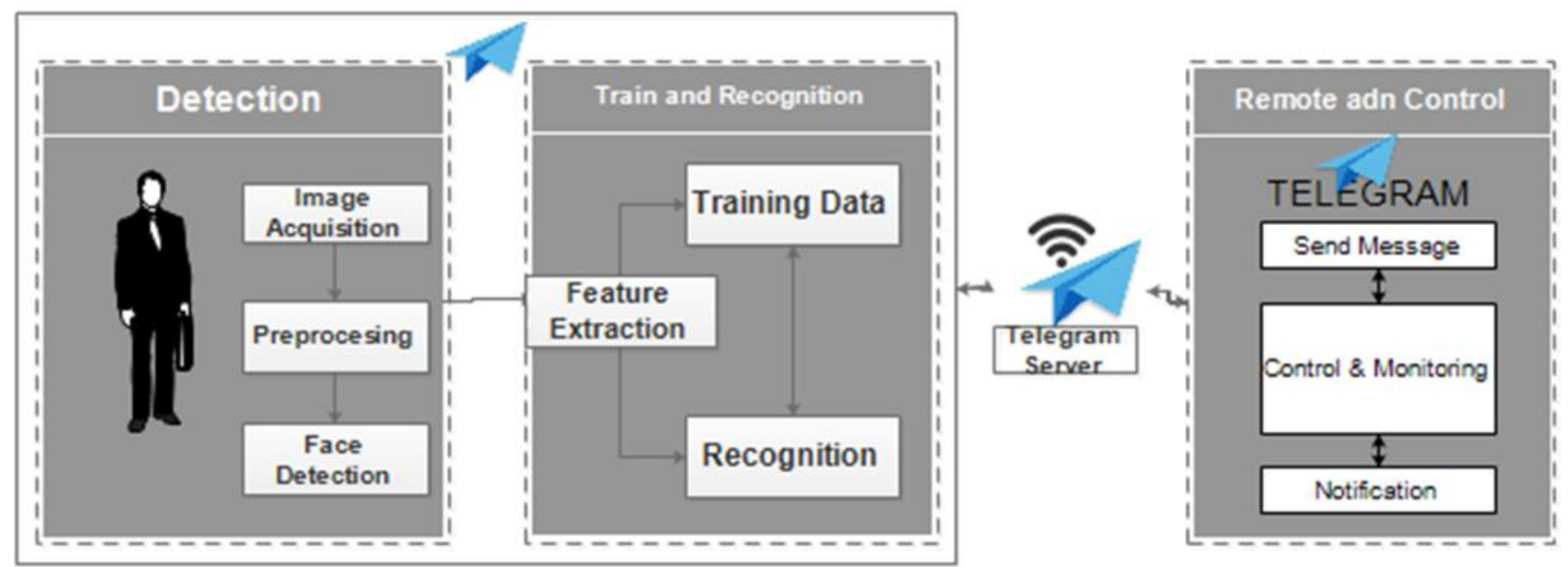

Figure 1: General Description

The Integration of Telegram Bot with face recognition in smart homes is a system of hardware devices that can con-trol and monitor a person's arrival remotely by using the Instant Messenger app, that is Telegram. Smart house con-trols are controls that can capture and transmit image data using Telegram apps by sending commands that are avail-able in the system. OpenCV Library is used to detect and recognize face image, create database and match face im-age data with database. The result of face detection and recognition are sent to users via the Messenger Telegram app.

To briefly illustrate who can use the system and what can be done, case diagrams is used. Through the use case diagram, we can know the functions that exist in the system 


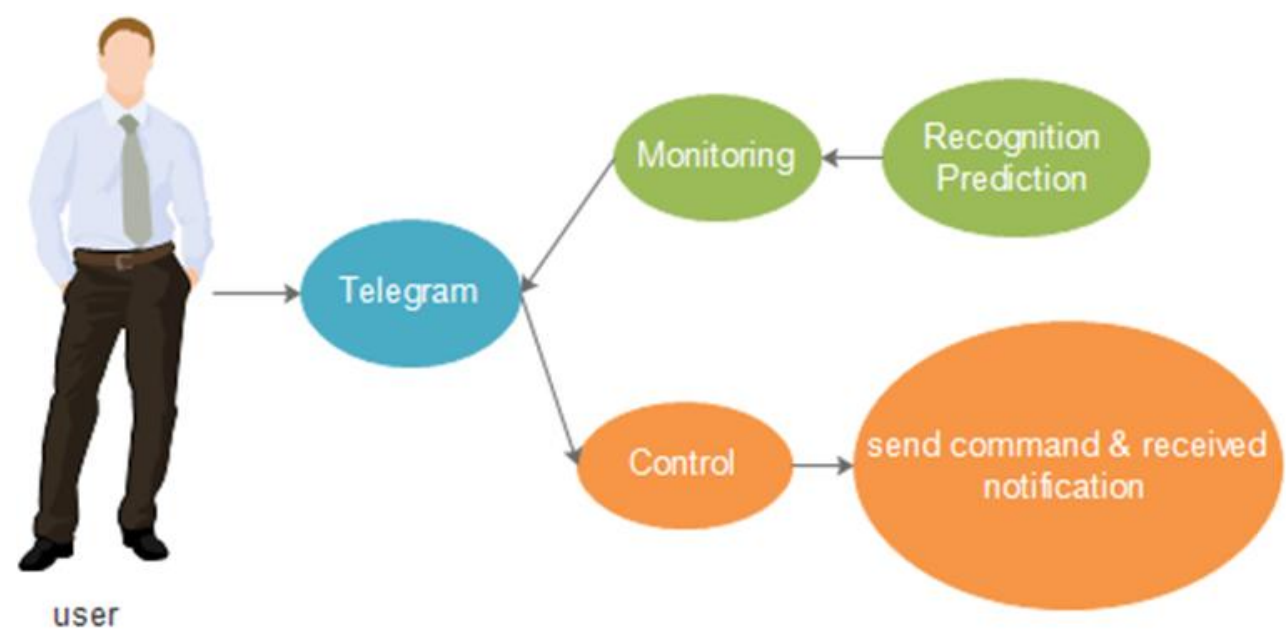

Figure 2: Use Case Diagram

Figure 2 is a use case diagram facial recognition system as a smart home feature where the actor who uses the system. The users who use Telegram can monitor and control home circumstances in real-time. Controls are used to send commands to capture an image which is then sent back to the user via Telegram Bot. The function of the monitor is to receive the results of face detection captured by the system. The results of the monitor is in the form of face capture and prediction of facial recognition made by the system built.

\subsection{OpenCV}

Open CV stands for Open Computer Vision, an open source library dedicated to image processing. OpenCV has the advantage of being a multi-platform framework; supports Windows and Linux, and more recently, Mac OS X. OpenCV uses a face detector type called Haar Cascade classifier [7]. The OpenCV function will be used for face recognition contained in some modules.

a) CalcCovarMatrixEx: Calculates covariance matri-ces for groups of input objects

b) CalcEigenObjects: Calculates the orthonormal base of the eigen and the average object for the group of input objects

c) CalcDecompCoeff: Calculates the decomposition coefficient of the input object

d) EigenDecomposite: Calculates all decomposition coefficients for the input object

EigenProjection: Calculates the projection of the object into the eigenv sub-space.

\subsection{Eigenface}

Eigenface was first developed by Matthew Turk and Alex Pentland of the Vision and Modeling Group, The Media Laboratory, Massachusetts Institute of Technol-ogy in 1987. This method was refined by Turk and Pent-land in 1991. The basic principle of the Eigenface Method is a way to extract relevant information from a face image and convert it into the most efficient set of codes and compare face codes with the database, the database contains a variety of faces that have been en-coded similarly. The Eigenface algorithm is quite simple, such as determining the Eigenvector in the image in the database and matching it with Eigenvalue on the training face (identified facial image). Training image is repre-sented in a flat vector and merged together into a single matrix. The Eigenvector is then extracted and stored into a temporary file or database

\subsection{Telegram}

Telegram is an instant messaging app like most apps such as Viver, WhatsApp, and LINE that gives users the ease of communicating with all users of Telegram apps. Telegram app is a cloud-based app so messaging is much faster. Telegram apps can be accessed through the web and their sync is much faster due to cloud-based. Tel-gram can be accessed through the web, making it easier for the users if they forget to bring the smartphone. Tele-gram feature is capable of sending files with a maximum of $1.5 \mathrm{gb}$ and has a bot capable of ease the user's work and it can be use to play games. Bot is a machine made to alleviate human work. Telegram Bot is a machine made on Telegram application that serves to lighten the user's work. Telegram Bots usually have the ability of ar-tificial intelligence to help users. The image search bot is one of the bot utilities used to search for the desired im-age without searching in the search engine.

\section{FEATURES OF THE PROPOSED SYSTEM \\ 5.1 Registration Face/Training Images}

The first step in the registration process is by filling the data in the form of the name of the owner, before all the data stored, face detection is process from the video image then captured into image data (photo), when the face is detected then the photo will be cropped and the cropping results are converted into grayscale image with specified size, the grayscale image is converted into a flat vector or one-dimensional array. The next stage is Eigenface extrac-tion, this process is done in order to get Eigenface weight or weight value of the image. After all the process has been done, then the data is stored into one between the identity with the weight value that has been obtained

\subsection{Face Recognition}

The first step in the process of face recognition is taking a new image of the recording process that runs, the face detection process of the image, when the face is detected then cropping the image and the results will be converted into grayscale image with the specified image size, gray-scale image is converted into flat vector or one-dimensional array. The next stage is Eigenface extraction, this process is done to get Eigenface weight or weight value of the image. Eigenface weight or weight value of the image is used to compare between images stored in the database with the image that is 
identified, the identified image data is the im-age data that has the number of minimum error value.

\subsection{Telegram Bot Integration}

This feature is used to monitor and control the state of the house in real-time. The controls are used to send com-mands to capture an image which is then sent back to the user via Telegram Bot. The function of the monitor is to receive the results of face detection which is captured by the system. The results of the monitor is in the form of face capture and prediction of facial recognition made by the system built.

\section{RESULTS}

The trial of the system is obtained by testing the registra-tion system of database creation and followed by recogni-tion system. The discussion is conducted to determine the factors that affect the identification system.

\subsection{The Trial of Face Registration System}

The trial of face recognition system of Smart House Features which is used to identify the face has a scheme as follows:

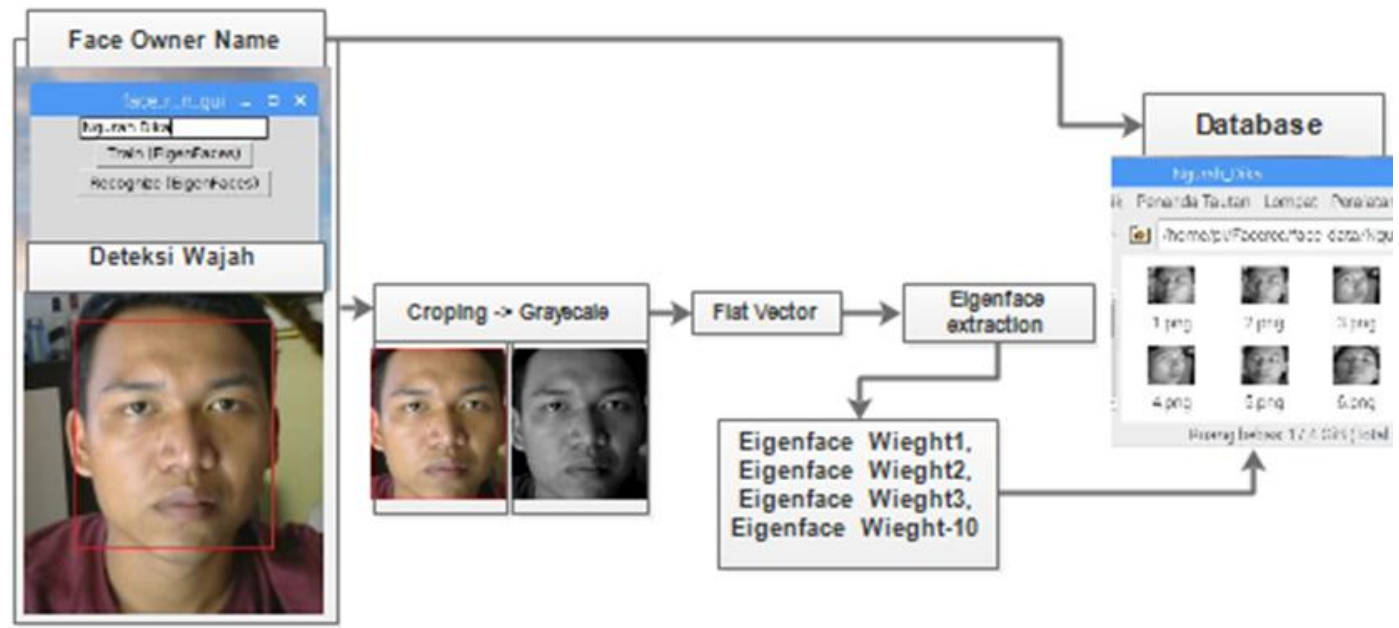

Figure 3: Train Secheme

The registration begins with inputting the owner's name, then the picture will be resized with 320x240 size pixels and face detection will be done. When the face is detected, the picture will be cropped and the results are converted into grayscale image. Face detection is done by searching the midpoint of the face, left boundary, right border, upper limit and lower limit.

\subsection{The Test Face Recognition}

The Test Face Recognition system of Smart House Features which is used to identify the face has a scheme as follows:

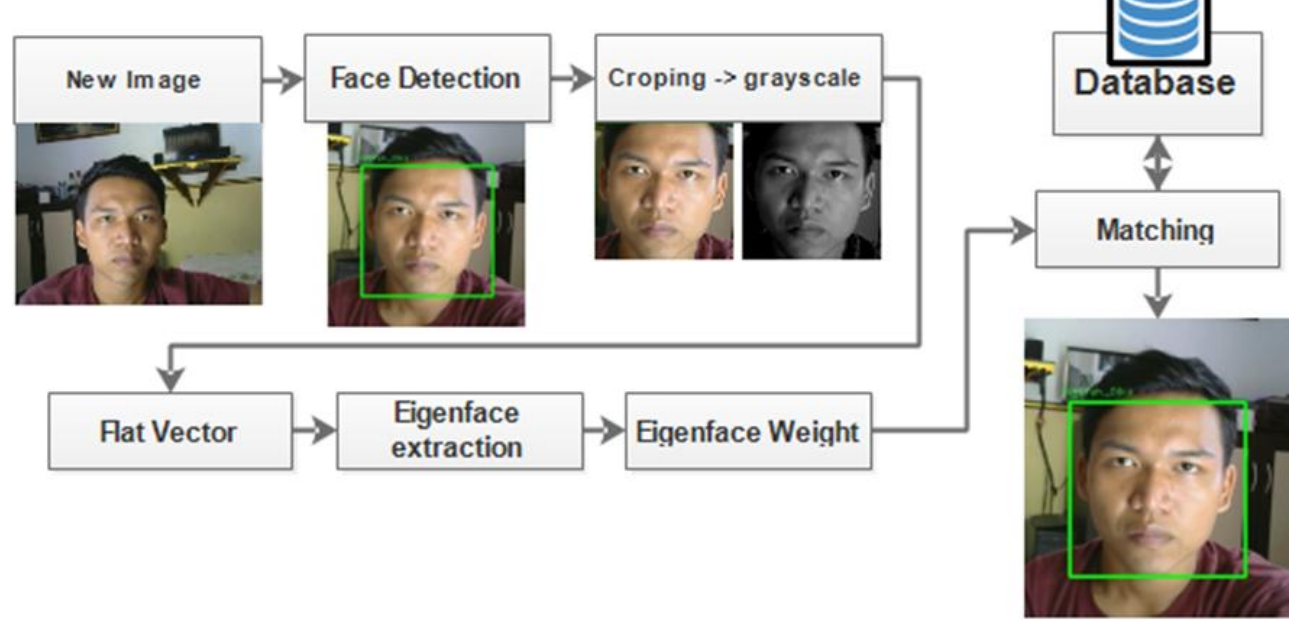

Figure 4: Face Recognition Scheme

The first step in the process of recognizing the face is by taking a new image of the recording process that runs, then the process of face detection will ne done, the face that has been detected will be processed so that it will become a flat vector. The next is Eigenface ectraction, this process will get the weight or weight value of the image.
The test identification is used 5 people as an object and performed 5 times repetition on each object. The test results are divided into 2, namely success rate (SR) and false accept rate (FAR). The success rate (SR) is seen from the conformity of the object with the result of the identification, whereas the incorrect level of recognition is seen from the mismatch of the object with the result of identification. The results of the identification test are shown in Table 1. 
Tabel 1. Test results identification

\begin{tabular}{llll}
\hline User Name & Many Trials & FAR & SR \\
\hline Nana & 5 & 0 & 5 \\
Juniari & 5 & 0 & 5 \\
Ratih & 5 & 1 & 4 \\
Putri & 5 & 1 & 4 \\
Ananta & 5 & 2 & 3 \\
\hline Total & 25 & 4 & 21 \\
\hline
\end{tabular}

Success Rate (SR)

$21 / 25 \times 100 \%=84 \%$
False Accet Rate (FAR)

$$
4 / 25 \times 100 \%=16 \%
$$

From the total of 25 identification tests, 21 identifications were correct and 4 identification were errors. It can be concluded that the percentage of all trials, the identification success rate or SR is $84 \%$ and false accept rate or FAR is $16 \%$. The percentage of success rate and the incorrect level of recognition is also influenced by several factors, such as face position and light intensity at the time of registration and when identification of face image

\subsection{Test Remote}

The test of face detection feature on Telegram Bot used to receive messages from the system when there is a detected face image that has a schematic shown in Figure 5 .

Percentage

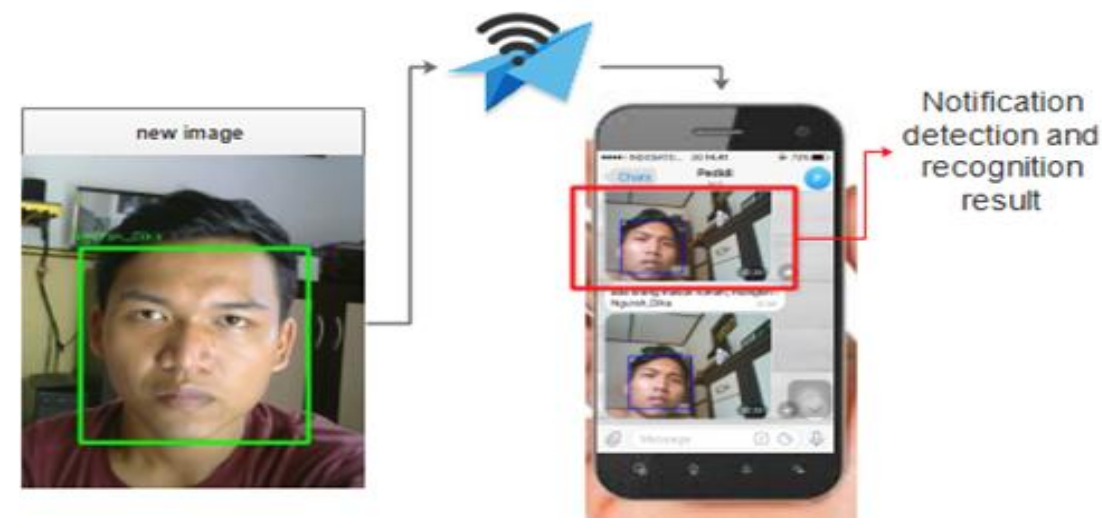

Figure 5: Telegram Bot Notifications

The test in Figure 5 shows when the system detects the presence of a face image, then the system will send the image data to the user via Telegram application

\subsection{The Test Control}

The test control using Telegram Bot is used to give commands on the system by sending messages commands from telegram users to telegram systems that have the scheme shown on Figure 7.

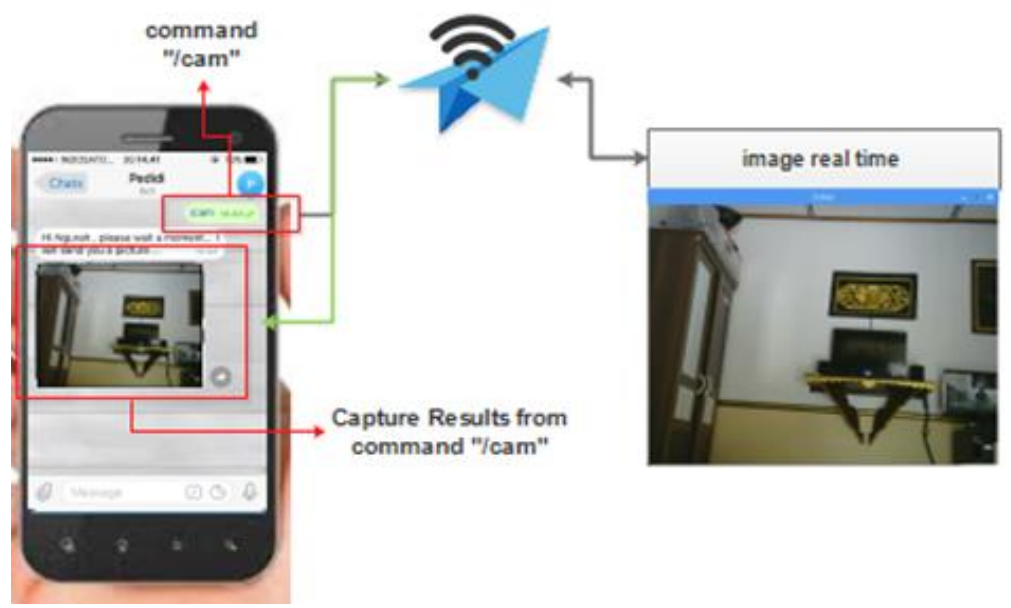

Figure 6. Telegram Bot Control

Figure 7 is a remote test using the Telegram app by sending the "/ cam" command message. The messages received and processed by the system, and the results of the processing are sent back to the system user in the form of real-time image capture data

\section{CONCLUTION}

The face recognition system as a smart home feature is designed and built to be implemented in smart homes by utilizing Telegram instant messaging applications as remote controls. The method used is Eigenface method. Based on 25 times identification, tge result of telegram integration with face recognition of this system obtained $84 \%$ percent of success rate or SR and $16 \%$ percent of misplaced or FAR rate 
in recognition. The percentage of success rate and the incorrect or misplaced level of recognition is also influenced by several factors, such as face position and light intensity at the time of registration and when identification of face image

\section{REFERENCES}

[1] A. A. K. Oka Sudana, I. K. G. Darma Putra, and A. Arismandika, 2014. "Face recognition system on android using Eigenface method," Journal Theoretical Applied Information Technology, vol. 61, no. 1, pp. 128-134.

[2] I Ketut Gede Darma Putra, 2010. "High Performance Palmprint Identification System Based On Two Dimensional Gabor," TELKOMNIKA, vol. 8, no. 1, pp. 309-318.

[3] Dwi Rusjayanthi, 2013 "Deviasi, dan K-Means Clustering," Lontar Komputer: Jurnal Ilmiah Teknologi Informasi, vol. 4, no. 2, pp. 265-276.

[4] Piarsa I Nyoman, Suar Wibawa, Arya Sasmita, Adi Purnawan, 2016. "Rancang Bangun Prototipe Sistem Monitoring dan Kontrol Visual Keamanan Rumah
Berbiaya Murah". Seminar Nasional Sains dan Teknologi (Senastek), Denpasar Bali.

[5] Prof .T Venkat Narayana Rao, D Vishal Reddy, and Rutwik V Jangam, 2015. "Face Detection E-Attendence System," International Journal Computer Trends and Technology, vol. 27, no. 3, pp. 152-155.

[6] IG. P. Fajar Pranadi. Sudhana, 2013. "Sampul dan Moment," Lontar Komputer: Jurnal Ilmiah Teknologi Informasi, vol. 4, no. 2, pp. 277-288.

[7] S. Emami and V. Petruț, 2012. "Facial Recognition using OpenCV", Journal of Mobile, Embedded and Distributed Systems, vol. IV, no. 1,

[8] Balaji, S., Murugaiyan, M., 2012. Waterfall vs. V-Model vs. Agile: A comparative study on SDLC. International Journal of Information Technology and Business Management 2(1), 177-188.

[9] Marijeta Slavkovic, Dubravka Jevtic. 2012. "Face Recognition Using Eigenface Approach*”. Serbian Journal of Electrical Engineering, Vol.9, No. 1, 